\title{
Cluster randomised trials in the medical literature: two bibliometric surveys J Martin Bland*
}

\author{
Address: Department of Health Sciences, University of York, York YO10 5DD, United Kingdom \\ Email: J Martin Bland* - mb55@york.ac.uk \\ * Corresponding author
}

Published: 13 August 2004

BMC Medical Research Methodology 2004, 4:2I doi:10.1/86/147|-2288-4-2I

This article is available from: http://www.biomedcentral.com/|47|-2288/4/2I

(C) 2004 Bland; licensee BioMed Central Ltd.

This is an open-access article distributed under the terms of the Creative Commons Attribution License (http://creativecommons.org/licenses/by/2.0), which permits unrestricted use, distribution, and reproduction in any medium, provided the original work is properly cited.
Received: 12 May 2004

Accepted: 13 August 2004

\begin{abstract}
Background: Several reviews of published cluster randomised trials have reported that about half did not take clustering into account in the analysis, which was thus incorrect and potentially misleading. In this paper I ask whether cluster randomised trials are increasing in both number and quality of reporting.

Methods: Computer search for papers on cluster randomised trials since 1980, hand search of trial reports published in selected volumes of the British Medical Journal over 20 years.

Results: There has been a large increase in the numbers of methodological papers and of trial reports using the term 'cluster random' in recent years, with about equal numbers of each type of paper. The British Medical Journal contained more such reports than any other journal. In this journal there was a corresponding increase over time in the number of trials where subjects were randomised in clusters. In 2003 all reports showed awareness of the need to allow for clustering in the analysis. In 1993 and before clustering was ignored in most such trials.
\end{abstract}

Conclusion: Cluster trials are becoming more frequent and reporting is of higher quality. Perhaps statistician pressure works.

\section{Background}

Cluster randomised trials are those where research subjects are not allocated to treatments independently, but as a group. For example, in a study of counselling patients on physical activity in general practice, practices were allocated to counselling or control and patients aged 40-79 years who attended during a five day period and who did not take regular exercise were invited to take part. Patients in the same practice received the same treatment, counselling or usual care, depending on how the practice was allocated. [1] The group of patients within the general practice formed a cluster.
Members of a cluster will be more like one another than they are like members of other clusters and we need to take this into account in the analysis, and preferably the design, of the study. Methods which ignore clustering may mislead, because they assume that all subjects provide independent observations. Applying simple statistical methods to such data, without taking the clustering into account, can lead to confidence intervals which are too narrow and $\mathrm{P}$ values which are too small.

There has been an increasing interest in cluster randomised trials over the past 20 years. For example, by the end of 2003 the British Medical Journal Statistics Notes on this topic [2-7] had been cited 121 times. 
Table I: Some reviews of published cluster randomised trials

\begin{tabular}{|c|c|c|c|c|}
\hline Authors & Source of trials & Years & $\begin{array}{l}\text { Clustering allowed for } \\
\text { in sample size }\end{array}$ & $\begin{array}{l}\text { Clustering allowed for in } \\
\text { analysis }\end{array}$ \\
\hline Donner et al. [8] & $\begin{array}{l}16 \text { non-therapeutic intervention } \\
\text { trials }\end{array}$ & $1979-1989$ & $<20 \%$ & $<50 \%$ \\
\hline Simpson et al. [9] & $\begin{array}{l}21 \text { trials from American Journal of } \\
\text { Public Health and Preventive } \\
\text { Medicine }\end{array}$ & $1990-1993$ & $19 \%$ & $57 \%$ \\
\hline Isaakidis and loannidis [ $\mathrm{I} \mathrm{I}]$ & $5 \mathrm{I}$ trials in Sub-Saharan Africa & $\begin{array}{l}1973-2001 \text { (half post } \\
1995)\end{array}$ & $20 \%$ & $37 \%$ \\
\hline Puffer et al. [10] & $\begin{array}{l}36 \text { trials in British Medical Journal, } \\
\text { Lancet, and New England Journal of } \\
\text { Medicine }\end{array}$ & $1997-2002$ & $56 \%$ & $92 \%$ a \\
\hline Eldridge et al. [12] & 152 trials in primary health care & $1997-2000$ & $9 \%$ & $59 \%$ \\
\hline Varnell et al. [13] & $\begin{array}{l}60 \text { trials in American Journal of } \\
\text { Public Health and Preventive } \\
\text { Medicine }\end{array}$ & $1998-2002$ & $20 \%$ & $\begin{array}{l}54 \% \text { (all analyses) }+25 \% \\
\text { (some analyses only) }\end{array}$ \\
\hline
\end{tabular}

a My review of trials identified by Puffer et al. [10]

There have been several reviews of published cluster randomised trials [8-13] (Table 1). All but Puffer et al. [10] reported that very few trials had sample size calculations which included clustering and about half took clustering into account in the analysis, fewer in the African studies reported by Isaakidis and Ioannidis. [11] Puffer et al. [10] did not mention whether trials failed to take clustering into account in the analysis. My own review of their trials as listed on the British Medical Journal website found that only 3 out of 36 ignored clustering. The review of the American Journal of Public Health and Preventive Medicine in 1998 - 2002 [13] is especially interesting because it attempted to replicate an earlier study [9] in the same journals. There was an increase in the number of reports of cluster randomised trials: 12.3 studies were reported per year in 1998 - 2002 compared to 5.3 studies per year in 1990 - 1993. [9] The quality of the analysis may have improved, but such assessments are subjective and very difficult to compare between reviews.

It is understandable that papers do not report sample size calculations, as often these are omitted from papers entirely, sometimes by the request of the journal to save space. It can be argued (though I would not do so) that once we have carried out a study, the sample size calculations are not particularly informative. Analysis which ignores the clustering, however, can be highly misleading, finding significant differences where there are none. We may have incorrect conclusions in the literature, which are then uncritically repeated and become false knowledge.

We should not be surprised that clustering is ignored. In the past, few textbooks have cautioned against this and the assumption of independence of observations is seldom stressed. Many statisticians will admit to having incorrectly ignored clustering in the analysis of clustered designs, including myself when I was younger and more ignorant than today. However, it can be very important.

In this paper I attempt to chart the changes in both the number of cluster randomised trials reported and the proportion of these reports where clustering has been taken into account in the analysis.

\section{Methods}

I first carried out a search on the ISI Web of Science, looking for papers on cluster randomisation and reports of trials. I classified these by type (trial report or methodological article), year of publication, and journal.

To identify cluster randomised trials we have to read the papers. We cannot tell whether a trial is cluster randomised from title, keywords, or abstract. Many authors are not aware of the importance of clustering and do not mention it. In this paper I report the results of a hand search of the British Medical Journal. I identified and scanned all papers reporting trials for the years 1983, $1988,1993,1998$, and 2003, recording any where subjects were allocated in clusters. I excluded any studies where subjects were not allocated to groups by the investigator, for example several comparisons of fund-holding and non-fund-holding general practices.

For each trial identified, I noted whether clustering had been taken into account in the analysis. There are several approaches which can be used to allow for clustering. The easiest is to calculate a summary statistic for each cluster. [4] This is usually a mean for a continuous outcome or a proportion for a dichotomous outcome. We can also use robust variance estimates, general estimating equation 
models (GEEs), multilevel modelling, Bayesian hierarchical models, and several other techniques. Any method which takes into account the clustering should be an improvement compared to methods which do not.

I also noted whether ignoring the possible effects of clustering might have an important effect on the conclusions. Clustering may result in P values and confidence intervals which are sufficiently biased to have a major effect if any of the following are true: the cluster size is large, the number of clusters is small, or the intra-cluster correlation coefficient is large. Whether any of these applies in a trial which ignores clustering is a matter of judgement.

\section{Results}

\section{A computer search for cluster randomised trials}

Figure 1 shows the result of a search on the ISI Web of Science, looking for papers on cluster randomisation and reports of trials. I found that other terms, such as 'group randomised' did not work, as I got hundreds of abstracts with 'patients were in two groups, randomised to active or control treatments'.

There are many potential biases. In the first part of the period, the Web of Science database did not include abstracts, so there was less opportunity to pick up the search terms. More recently, several journals began to include a description of the trial design in the title of the paper, for example 'Effect on hip fractures of increased use of hip protectors in nursing homes: cluster randomised controlled trial'. [14] This will increase the detection rate. These design descriptions are not always correct, nor does the cluster randomised nature of the trial necessarily appear in the description. Also, many authors will not be aware of the importance of clustering and will not mention it. These factors will reduce detection. Hence this is not a thorough search and will have missed many studies, but it might give an idea of the increase in activity.

I divided the papers into those which were methodological, either educating researchers into the appropriate design and analysis of cluster randomised trials or developing new methods of analysing such trials, and those reporting actual trials. The data for 2000 and 2001 includes special issues of Statistics in Medicine and Statistical Methods in Medical Research on cluster randomisation, so there were a larger number of methodological papers than might be expected in those years. The numbers of papers found in the two categories were similar in each year before 2001: as many papers were about how to do such trials as were reports of actual trials. It is hard to believe that there are so few such trials being reported and it is likely that many have been reported without any acknowledgement of the importance of clustering.
All the papers up to 1990 are due to Donner and his colleagues. $[8,15,16]$ However, it was impossible to identify papers which used older terminology. A paper by Cornfield [17] 'Randomisation by group: a formal analysis' includes the following statement 'Randomization by cluster accompanied by an analysis appropriate to randomization by individual is an exercise in self-deception, however, and should be discouraged.' This would not be found by the search. The book on cluster randomization by Murray [18] is called The Design and Analysis of GroupRandomized Trials.

The British Medical Journal was the journal most frequently represented in the survey, no fewer than 43 of the 332 publications found, $13 \%$, appearing there. The next was Statistics in Medicine with 39 publications (12\%), all methodological, then the British Journal of General Practice with 17 (5\%), Controlled Clinical Trials with 16 (5\%), and Family Practice with $10(3 \%)$. Figure 1 shows that papers in the British Medical Journal reflect the literature as a whole. The first paper in the BMJ was a report of a trial, [19] which was followed four years later by a series of short educational articles. [3,4,6,7]

When I first did the search reported in Figure 1, I was surprised by how few trials were reported. My subjective impression was that there were many more cluster randomised trials than I had found. I therefore decided to carry out a small survey of journals to find out whether the dramatic increase shown in Figure 1 was real. As the British Medical Journal had most reports and had been published for many years, this was the obvious journal with which to begin.

\section{A survey of papers in the British Medical Journal}

The results of the search are shown in Table 2. As Table 2 shows only reports of trials, it does not include all the BMJ papers in Figure 1, which also includes methodological papers. A list of all papers reviewed is given in the additional file: papers in the survey. Only one of the trials in survey [1] cited any of the BMJ Statistics Notes on clustering. [2-7]

The noted query relates to a paper in which the authors stated that 'Univariate comparisons were calculated by $\mathrm{t}$ test and $\chi^{2}$ analysis. The role of potential covariates was explored using linear regression specified as a two level model (practice and individual) using the software package MLn'. [20] I could find no multilevel modelling in this paper, but a lot of $t$ and $\chi^{2}$ tests. This was a trial of community based management in failure to thrive by babies. Thirty eight primary care teams were randomly allocated to intervention or control and all children identified in the practice were offered the same intervention, so clearly clustering should be taken into account. 

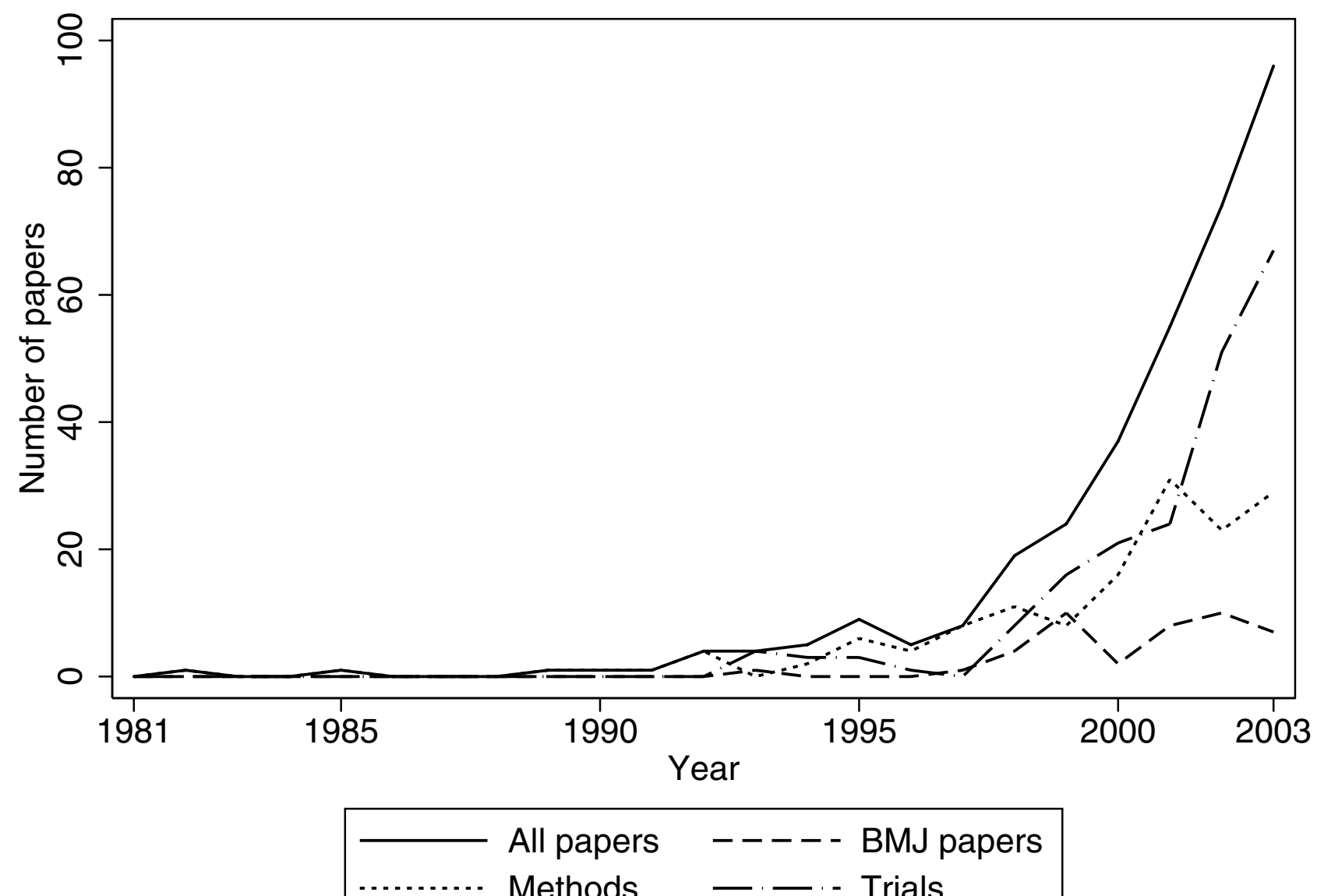

Methods _- - - Trials

Figure I

Results of a Web of Science search. Results of a Web of Science search on: randomi* in clusters OR cluster randomi*, up to the end of 2003.

Table 2: Result of a hand search for cluster randomised trials in the British Medical Journal

\begin{tabular}{llllll}
\hline Year & Vol & Trials & Clustering ignored & $\begin{array}{l}\text { Ignoring clustering judged as } \\
\text { important }\end{array}$ & $\begin{array}{l}\text { Found in Web of Science } \\
\text { search }\end{array}$ \\
\hline 2003 & $326-7$ & 9 & 0 & 0 & 5 \\
1998 & $316-7$ & 4 & $1(?)$ & 1 & 0 \\
1993 & $306-7$ & 4 & 3 & 2 & 0 \\
1988 & $296-7$ & 0 & 0 & 0 & 0 \\
1983 & $286-7$ & 1 & 1 & 1 & 0 \\
\hline
\end{tabular}

? doubtful whether clustering taken into account

The trials which I regarded as failing to take the clustering into account were as follows. Russell et al. [21] investigated the effect of nicotine chewing gum as an adjunct to general-practitioners advice against smoking. Subjects were 'assigned by week of attendance (in a balanced design) to one of three groups (a) non-intervention con- 
trols (b) advice and booklet (c) advice and booklet plus the offer of nicotine gum.' There were 6 practices, with recruitment over 3 weeks, one week to each regime. The study was analysed by chi-squared tests. As the clusters were large, with 1938 subjects in 18 clusters, clustering should have been taken into account.

Rink et al. [22] investigated the impact of introducing near patient testing for standard investigations in general practice. Twelve practices were used, and some given the equipment and some not in a cross-over design. Analysis used paired t tests, unpaired t tests, odds ratios, ratios of proportions with confidence intervals, and chi squared tests, none of which took clustering into account.

In a trial of clinical guidelines to improve general-practice management and referral of infertile couples, Emslie et al. [23] randomised 82 general practices in Grampian region and studied 100 couples in each group. However, the main outcome measure was whether the general practitioner had taken a full sexual history and examined and investigated both partners appropriately. The cluster size may be small but the cluster effect may be large. The GP should be the unit of analysis here as opposed to the couple, as done in the paper.

The trial where I judged ignoring clustering to be unimportant had many very small clusters. Wetsteyn and Degeus [24] compared 3 regimens for malaria prophylaxis in travellers to Africa. Members of one family were allocated to one regimen and the results analysed using a chisquared test.

Only five of the 18 trials had been found in the Web of Science search, showing that that was indeed an underestimate. However, the growth in numbers of trials is indicated by both electronic and hand searches.

\section{Discussion}

A bibliometric survey has suggested a rapid increase in the number of cluster randomised trials, many of which appeared in the British Medical Journal. A hand search of the British Medical Journal has confirmed this increase, at least in this journal. Although the effects of clustering have often been ignored in trials, producing potentially misleading conclusions, the situation has certainly improved in the British Medical Journal. This has followed many articles on the topic in the Journal. Perhaps statistician pressure works.

Identification of cluster allocation is subjective. I included one year, 1998, also searched by Puffer et al. [10] and identified four trials where Puffer et al. [10] identified only one. My assessments of whether clustering has been taken into account and whether ignoring it might be important are also subjective. Nevertheless, I think that the general conclusion of increasing activity and better reporting of trials, at least in the British Medical Journal, is valid. Whether we would find a similar improvement in other journals is less certain. It is likely that reporting of cluster randomised trials in the British Medical Journal is especially good, as the journal reports many such trials, has carried many articles on their correct analysis and reporting, has a fairly rigorous statistical refereeing system, [25-27] and is generally of a relatively high methodological standard. The BMJ's current statistical checklist [28] does not mention clusters, however. It would be possible to extend the survey to other journals where such trials are frequently reported, but these, too, might be more likely to adhere to sound principles of analysis and reporting than would journals where few such studies appear. The thought of hand-searching journals where no trials might be found does not appeal.

There are still many other aspects of trial reporting where improvement is possible $[10,12]$ but the picture drawn by this survey is encouraging. Methodologists need to keep up the pressure and to extend it to specialist journals. The recently published extension of the CONSORT statement to cluster randomised trials is to be welcomed. [29] We should also pursue other types of study where the unit of analysis is doubtful, such as those involving observations of multiple body parts in the same patient or multiple measurements on the same tissue treated as independent.

\section{Conclusions}

Cluster trials have become much more frequent since the mid 1990s. Reporting of these trials has improved and in the journal which publishes more than any other the quality had improved greatly. This improvement has followed a large number of articles advocating methods of analysis which take clustering into account, Perhaps statistician pressure works.

\section{Competing interests}

The author has been published frequently in the British Medical Journal, including articles written for payment.

\section{Authors' contributions}

$\mathrm{J}$. M. Bland is the sole contributor.

\section{Additional material}

\section{Additional File 1}

Papers in the survey List of papers in the survey of the BMJ, Word file. Click here for file

[http://www.biomedcentral.com/content/supplementary/14712288-4-21-S1.doc] 


\section{Acknowledgements}

I thank Douglas Altman, Sandra Eldridge, Sally Kerry, Jeremy Miles, and

David Torgerson for helpful comments on a draft.

\section{References}

I. Elley CR, Kerse N, Arroll B, Robinson E: Effectiveness of counselling patients on physical activity in general practice: cluster randomised controlled trial. Brit Med J 2003, 326:793-796.

2. Altman DG, Bland JM: Statistics Notes - Units of analysis. Brit Med J 1997, 3 | 4: I874.

3. Bland JM, Kerry SM: Statistics Notes - Trials randomised in clusters. Brit Med J 1997, 3 I 5:600.

4. Kerry SM, Bland JM: Statistics Notes - Analysis of a trial randomised in clusters. Brit Med J 1998, 3 1 6:54.

5. Bland JM, Kerry SM: Statistics Notes - Weighted comparison of means. Brit Med J 1998, 3 16:129.

6. Kerry SM, Bland JM: Statistics Notes - Sample size in cluster randomisation. Brit Med J 1998, 3 I 6:549.

7. Kerry SM, Bland JM: Statistics Notes - The intra-cluster correlation coefficient in cluster randomisation. Brit Med J 1998 , 3 1 6: 1455.

8. Donner A, Brown KS, Brasher P: A methodological review of non-therapeutic intervention trials employing cluster randomization. 1979-1989. Int J Epidemiol 1990, I9:795-800.

9. Simpson JM, Klar N, Donner A: Accounting for cluster randomization - a review of primary prevention trials, 1990 through 1993. Am J Public Health 1995, 85: I 378-I 383.

10. Puffer S, Torgerson D, Watson J: Evidence for risk of bias in cluster randomised trials: review of recent trials published in three general medical journals. Brit Med J 2003, 327:785-789.

II. Isaakidis P, loannidis JPA: Evaluation of cluster randomized controlled trials in sub-Saharan Africa. Am J Epidemiol 2003, I 58:921-926.

12. Eldridge SM, Ashby D, Feder GS, Rudnicka AR, Ukoumunne OC: Lessons for cluster randomised trials in the 2 I st century: a systematic review of trials in primary care. Clin Trials 2004, I:80-90.

13. Varnell SP, Murray DM, Janega JB, Blitstein JL: Design and analysis of group-randomized trials: a review of recent practices. $A m$ J Public Health 2004, 94:393-399.

14. Meyer G, Warnke A, Bender R, Mühlhauser I: Effect on hip fractures of increased use of hip protectors in nursing homes: cluster randomised controlled trial. Brit Med J 2003, 326:76-78.

15. Donner A, Birkett N, Buck C: Randomization by cluster - sample-size requirements and analysis. Am J Epidemiol 198I, I | 4:906-9|4.

16. Donner A: An empirical-study of cluster randomization. Inl J Epidemiol 1982, $11: 283-286$

17. Cornfield J: Randomisation by group: $\mathbf{A}$ formal analysis. $A m \mathrm{~J}$ Epidemiol 1978, 108:100.

18. Murray DM: The Design and Analysis of Group-Randomized Trials Oxford: University Press; 1998.

19. Nutbeam D, Macaskill P, Smith C, Simpson JM, Catford J: Evaluation of 2 school smoking education-programs under normal classroom conditions. Brit Med J 1993, 306:102-107.

20. Wright CM, Callum J, Birks E, Jarvis S: Effect of community based management in failure to thrive: randomised controlled trial. Brit Med J 1998, 3 I 7:571-574.

21. Russell MAH, Merriman R, Stapleton J, Taylor W: Effect of nicotine chewing gum as an adjunct to general-practitioners advice against smoking. Brit Med J 1983, 287: 1782-I785.

22. Rink E, Hilton S, Szczepura A, Fletcher J, Sibbald B, Davies C, Freeling $P$, Stilwell J: Impact of introducing near patient testing for standard investigations in general-practice. Brit Med J 1993 , 307:775-778.

23. Emslie C, Grimshaw J, Templeton A: Do clinical guidelines improve general-practice management and referral of infertile couples? Brit Med J 1993, 306:1728-I73I.

24. Wetsteyn JCFM, Degeus A: Comparison of 3 regimens for malaria prophylaxis in travelers to East, Central, and Southern Africa. Brit Med J 1993, 307: I041-1043.

25. Gardner MJ, Altman DG, Jones DR, Machin D: Is the statistical assessment of papers submitted to the "British Medical Journal" effective? Brit Med J I983, 286: I485-8.
26. Altman DG, Gore SM, Gardner MJ, Pocock SJ: Statistical guidelines for contributors to medical journals. Brit Med J I983, 286: |489-93.

27. Gardner MJ, Machin D, Campbell MJ: Use of check lists in assessing the statistical content of medical studies. Brit Med J 1986, 292:810-2.

28. bmj.com - Advice to contributors [http://bmj.bmijournals.com/ advice/checklists.shtml\#gstatistical]

29. Campbell MK, Elbourne DR, Altman DG, for the CONSORT Group: The CONSORT statement: extension to cluster randomised trials. Brit Med J 2004, 328:702-708.

\section{Pre-publication history}

The pre-publication history for this paper can be accessed here:

http://www.biomedcentral.com/1471-2288/4/21/prepub
Publish with Biomed Central and every scientist can read your work free of charge

"BioMed Central will be the most significant development for disseminating the results of biomedical research in our lifetime. "

Sir Paul Nurse, Cancer Research UK

Your research papers will be:

- available free of charge to the entire biomedical community

- peer reviewed and published immediately upon acceptance

- cited in PubMed and archived on PubMed Central

- yours - you keep the copyright
BioMedcentral 